\title{
Highly Efficient Blue Electroluminescence Using Delayed- Fluorescence Emitters with Large Overlap Density between Luminescent and Ground States
}

\author{
Katsuyuki Shizu, ${ }^{\dagger, \$,}$ Hiroki Noda, ${ }^{\|}$Hiroyuki Tanaka, ${ }^{\dagger}$ Masatsugu Taneda, ${ }^{\dagger}$ \\ Motoyuki Uejima, ${ }^{\perp}$ Tohru Sato, ${ }^{\perp, \#}$ Kazuyoshi Tanaka, ${ }^{\perp}$ Hironori Kaji, ${ }^{\ddagger}$, and \\ Chihaya Adachi ${ }^{*}, \uparrow, \S, \nabla$
}

\footnotetext{
${ }^{\dagger}$ Center for Organic Photonics and Electronics Research (OPERA), Kyushu University, 744 Motooka, Nishi, Fukuoka 819-0395, Japan

Institute for Chemical Research, Kyoto University, Uji, Kyoto 611-0011, Japan

${ }^{\S}$ Japan Science and Technology Agency (JST), ERATO, Adachi Molecular Exciton Engineering Project, 744 Motooka, Nishi, Fukuoka 819-0395, Japan

"Department of Applied Chemistry and Biochemistry, Kyushu University, 744 Motooka, Nishi, Fukuoka 819-0395, Japan

${ }^{\perp}$ Department of Molecular Engineering, Graduate School of Engineering, Kyoto University, Kyoto 615-8510, Japan

\#Unit of Elements Strategy Initiative for Catalysts \& Batteries, Kyoto University, Kyoto 615-8510, Japan

${ }^{\nabla}$ International Institute for Carbon Neutral Energy Research (WPI-I2CNER), Kyushu University, 744 Motooka, Nishi, Fukuoka 819-0395, Japan
} 


\section{9-(4-(4,6-diphenyl-1,3,5-triazin-2-yl)phenyl)-9'-phenyl-9H,9' H-3,3'-bicarbazole}

\section{(BCzT)}

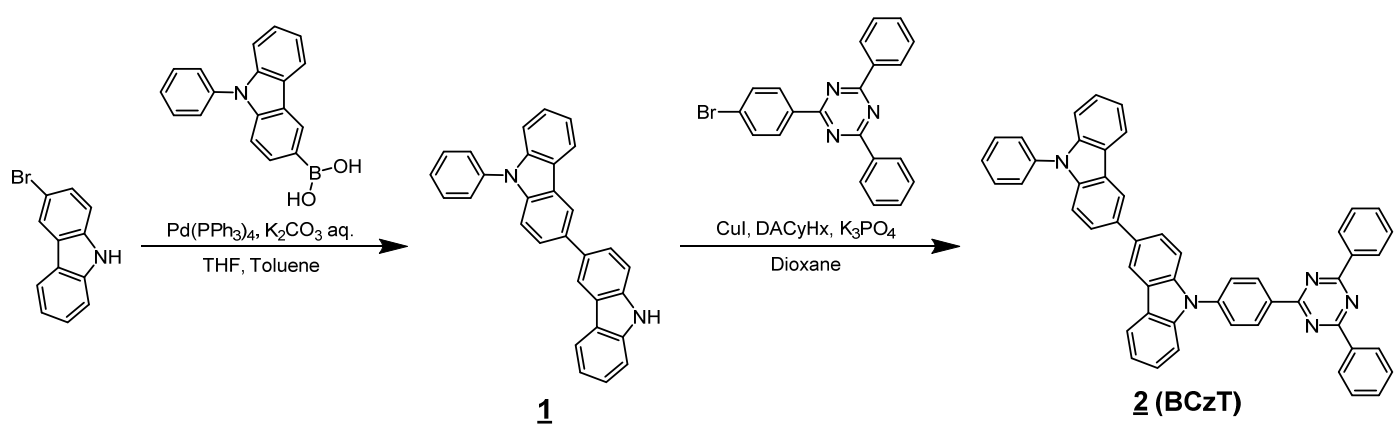

To an initial solution of $2.72 \mathrm{~g}$ of 3-bromocarbazole $(9.49 \mathrm{mmol}), 3.00 \mathrm{~g}$ of 9-phenylcarbazole-3-boronic acid $(10.4 \mathrm{mmol})$ and $121 \mathrm{mg}$ of tetrakis(triphenylphosphine) palladium $(0)\left(\mathrm{Pd}\left(\mathrm{PPh}_{3}\right)_{4}\right)(0.11 \mathrm{mmol})$ in $75 \mathrm{ml}$ of tetrahydrofuran (THF) and 50 $\mathrm{ml}$ of toluene, we added, while stirring, a solution of $2.89 \mathrm{~g}$ of potassium carbonate $\left(\mathrm{K}_{2} \mathrm{CO}_{3}\right)(20.0 \mathrm{mmol})$ in $30 \mathrm{ml}$ of water. The mixture was then stirred and refluxed for 2 $\mathrm{d}$. The cooled mixture was then partitioned between chloroform and water. The organic layer was separated, and the aqueous layer was extracted with the chloroform. The combined organic layers were washed with brine, dried over $\mathrm{Mg}_{2} \mathrm{SO}_{4}$, and concentrated in vacuo. Column chromatography of the solid residue (eluent: dichloromethane $/ n$-hexane $=1 / 4)$ afforded $2.96 \mathrm{~g}$ of a white product $(\underline{\mathbf{1}})(>76 \%)$.

A mixture of $1.23 \mathrm{~g}$ of $\underline{\mathbf{1}}$ (3.00 mmol), $1.16 \mathrm{~g}$ of 2-(4-bromophenyl)-4,6-diphenyl-1,3,5triazine $^{1}(3.00 \mathrm{mmol}), 140 \mathrm{mg}$ of copper (I) iodide $(0.75 \mathrm{mmol}), 1.27 \mathrm{~g}$ of tripotassium phosphate $\left(\mathrm{K}_{3} \mathrm{PO}_{4}\right)(6.00 \mathrm{mmol})$ and $260 \mathrm{mg}$ of $(1 R, 2 R)-(-)$-1,2-diaminocyclohexane (DACyHx) $(2.25 \mathrm{mmol})$ in $30 \mathrm{ml}$ of 1,4-dioxane was heated and stirred at $110^{\circ} \mathrm{C}$ for $4 \mathrm{~d}$. The cooled mixture was then partitioned between ethyl acetate and water. The organic layer was separated, and the aqueous layer was extracted with the ethyl acetate. The combined organic layers were washed with brine, dried over $\mathrm{Mg}_{2} \mathrm{SO}_{4}$, and concentrated in vacuo. Column chromatography of the solid residue (eluent: chloroform $/ n$-hexane $=$ $1 / 4)$ afforded $1.12 \mathrm{~g}$ of a yellow product $(\underline{\mathbf{2}})(>51 \%)$. This material was further purified by sublimation under reduced pressure conditions for OLED fabrication.

[NMR] ${ }^{1} \mathrm{H}$ NMR $\left(\mathrm{CDCl}_{3}, 400 \mathrm{MHz}\right) \delta=7.33(\mathrm{t}, 1 \mathrm{H}), 7.37(\mathrm{t}, 1 \mathrm{H}), 7.48(\mathrm{~m}, 4 \mathrm{H}), 7.52(\mathrm{~d}$, $1 \mathrm{H}), 7.64(\mathrm{~m}, 11 \mathrm{H}), 7.67(\mathrm{~d}, 1 \mathrm{H}), 7.80(\mathrm{~d}, 1 \mathrm{H}), 7.83(\mathrm{~d}, 1 \mathrm{H}), 7.88(\mathrm{~d}, 2 \mathrm{H}), 8.27(\mathrm{t}, 2 \mathrm{H})$, $8.49(\mathrm{~s}, 2 \mathrm{H}), 8.84(\mathrm{~d}, 4 \mathrm{H}), 9.06(\mathrm{~d}, 2 \mathrm{H})$.

[MS] MALDI-MS m/z calcd for $\mathrm{C}_{51} \mathrm{H}_{33} \mathrm{~N}_{5}$ : 716; found: 715 .

[Element analysis] Calcd for $\mathrm{C}_{51} \mathrm{H}_{33} \mathrm{~N}_{5}: \mathrm{C}, 85.57 ; \mathrm{H}, 4.65 ; \mathrm{N}, 9.78$; found: $\mathrm{C}, 85.61 ; \mathrm{H}$, $4.57 ; \mathrm{N}, 9.78$. 
9'-(4-(4,6-diphenyl-1,3,5-triazin-2-yl)phenyl)-9,9' '-diphenyl-9H,9' H,9' 'H-3,3' :6' ,3'"tercarbazole (TCzT)

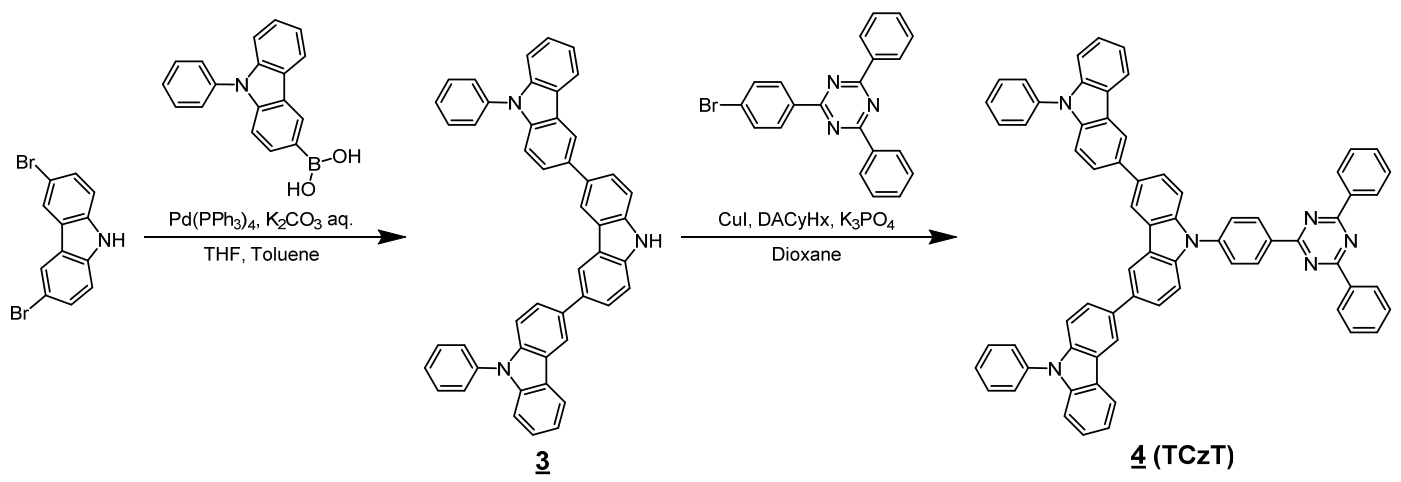

To an initial solution of $1.63 \mathrm{~g}$ of 3,6-dibromocarbazole $(5.00 \mathrm{mmol}), 2.87 \mathrm{~g}$ of 9-phenylcarbazole-3-boronic acid $(10.0 \mathrm{mmol})$ and $578 \mathrm{mg}$ of $\mathrm{Pd}\left(\mathrm{PPh}_{3}\right)_{4}(0.50 \mathrm{mmol})$ in $45 \mathrm{ml}$ of THF and $30 \mathrm{ml}$ of toluene, we added, while stirring, a solution of $2.76 \mathrm{~g}$ of $\mathrm{K}_{2} \mathrm{CO}_{3}(20.0 \mathrm{mmol})$ in $30 \mathrm{ml}$ of water. The mixture was then stirred and refluxed for $2 \mathrm{~d}$. The cooled mixture was then partitioned between ethyl acetate and water. The organic layer was separated, and the aqueous layer was extracted with the ethyl acetate. The combined organic layers were then washed with brine, dried over $\mathrm{Mg}_{2} \mathrm{SO}_{4}$, and concentrated in vacuo. The solid residue was washed with chloroform, filtered, and finally dried to afford $895 \mathrm{mg}$ of a white product $(\underline{\mathbf{3}})(1.38 \mathrm{mmol}$, crude). The crude product was then used directly without any further purification.

A mixture of $895 \mathrm{mg}$ of $\underline{\mathbf{3}} \quad(1.38 \quad \mathrm{mmol}), \quad 536 \mathrm{mg}$ of 2-(4-bromophenyl)-4,6-diphenyl-1,3,5-triazine ${ }^{1}$ (1.38 mmol), $26.7 \mathrm{mg}$ of copper (I) iodide $(0.14 \mathrm{mmol}), 586 \mathrm{mg}$ of $\mathrm{K}_{3} \mathrm{PO}_{4}(2.76 \mathrm{mmol})$ and $47.3 \mathrm{mg}$ of DACyHx $(0.41$ $\mathrm{mmol}$ ) in $10 \mathrm{ml}$ of 1,4-dioxane was heated and stirred at $110^{\circ} \mathrm{C}$ for $2 \mathrm{~d}$. The cooled mixture was then partitioned between ethyl acetate and water. The organic layer was separated, and the aqueous layer was extracted with the ethyl acetate. The combined organic layers were then washed with brine, dried over $\mathrm{Mg}_{2} \mathrm{SO}_{4}$, and concentrated in vacuo. The solid residue was washed with chloroform and collected by filtration to afford $819 \mathrm{mg}$ of a yellow product $(\underline{4})(>62 \%)$. This material was further purified by sublimation under reduced pressure conditions for OLED fabrication.

[NMR] ${ }^{1} \mathrm{H}$ NMR $\left(\mathrm{CDCl}_{3}, 400 \mathrm{MHz}\right) \delta=7.33(\mathrm{t}, 2 \mathrm{H}), 7.45(\mathrm{~m}, 4 \mathrm{H}), 7.50(\mathrm{~m}, 3 \mathrm{H}), 7.53$ $(\mathrm{d}, 2 \mathrm{H}), 7.64(\mathrm{~m}, 15 \mathrm{H}), 7.71(\mathrm{~d}, 2 \mathrm{H}), 7.83(\mathrm{~d}, 2 \mathrm{H}), 7.86(\mathrm{~d}, 2 \mathrm{H}), 7.93(\mathrm{~d}, 2 \mathrm{H}), 8.26(\mathrm{~d}$, $2 \mathrm{H}), 8.52(\mathrm{~s}, 2 \mathrm{H}), 8.59(\mathrm{~s}, 2 \mathrm{H}), 8.85(\mathrm{~d}, 4 \mathrm{H}), 9.08(\mathrm{~d}, 2 \mathrm{H})$.

[MS] MALDI-MS m/z calcd for $\mathrm{C}_{69} \mathrm{H}_{44} \mathrm{~N}_{6}$ : 957; found: 957.

[Element analysis] Calcd for $\mathrm{C}_{69} \mathrm{H}_{44} \mathrm{~N}_{6}$ : C, 86.59; H, 4.63; N, 8.78; found: C, 86.47; H, 4.61 ; N, 8.75. 
$\mathrm{S}_{1} \leftarrow \mathrm{S}_{0}$ excitation energies and electronic transitions for $\mathrm{BCzT}$ and $\mathrm{CzT}$ calculated with the B3LYP, CAM-B3LYP, $\omega B 97 X-D$, and M06-2X functionals and the cc-pVDZ basis set.

Supplementary Table S1: Excitation energies and oscillator strengths of $\mathrm{S}_{1}$ for BCzT and CzT calculated using the B3LYP, CAM-B3LYP, $\omega$ B97X-D, and M06-2X functionals and the cc-pVDZ basis set.

\begin{tabular}{|c|c|c|c|}
\hline Compound & Functional & Excitation energy $(\mathrm{nm})$ & Oscillator strength \\
\hline \multirow{4}{*}{$\mathrm{BCzT}$} & B3LYP & 451 & 0.2125 \\
\hline & CAM-B3LYP & 317 & 0.6929 \\
\hline & $\omega B 97 X-D$ & 303 & 0.8633 \\
\hline & M06-2X & 328 & 0.6762 \\
\hline \multirow[t]{4}{*}{ CzT } & B3LYP & 427 & 0.0023 \\
\hline & CAM-B3LYP & 351 & 0.0054 \\
\hline & $\omega B 97 X-D$ & 338 & 0.0147 \\
\hline & M06-2X & 317 & 0.0055 \\
\hline
\end{tabular}

Supplementary Table S2: Excitation coefficients higher than 0.1 of $\mathrm{S}_{1}$ for BCzT and CzT calculated using the CAM-B3LYP functional and cc-pVDZ basis set.

\begin{tabular}{ccccc}
\hline Compound & $\mathrm{S}_{1}$ energy $(\mathrm{nm})$ & \multicolumn{2}{c}{ Transition } & Coefficient \\
\hline BCzT & 317 & HOMO-3 & $\rightarrow$ LUMO & -0.10651 \\
& & HOMO-2 & $\rightarrow$ LUMO & -0.10180 \\
& HOMO-1 $\rightarrow$ LUMO & 0.32182 \\
& HOMO-1 $\rightarrow$ LUMO+4 & 0.11007 \\
& HOMO $\rightarrow$ LUMO & 0.53089 \\
CzT & \multirow{3}{*}{351} & HOMO $\rightarrow$ LUMO+4 & 0.17578 \\
& HOMO-3 $\rightarrow$ LUMO & 0.27208 \\
& HOMO-2 $\rightarrow$ LUMO & 0.26407 \\
& HOMO-1 $\rightarrow$ LUMO & 0.24799 \\
& HOMO & $\rightarrow$ LUMO & 0.50438 \\
\hline
\end{tabular}


Molecular orbitals involved in $S_{1} \leftarrow S_{0}$ excitation other than HOMO and LUMO of BCzT and CzT

(a) $\mathrm{BCzT}$
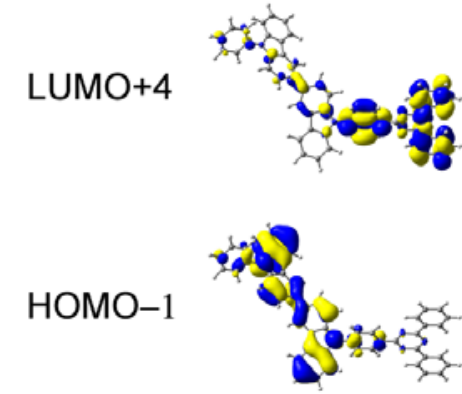

HOMO-2

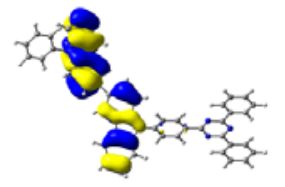

HOMO-3

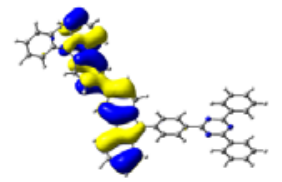

HOMO-1

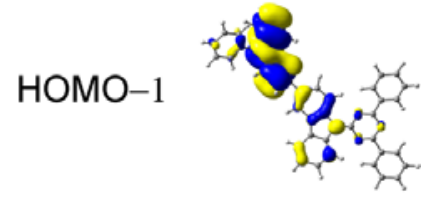

(b) $\mathrm{CzT}$

HOMO-2

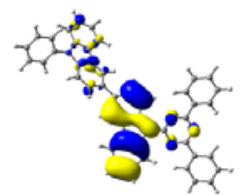

HOMO-3

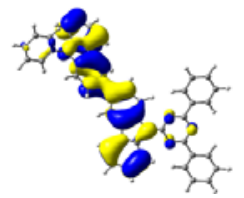

Supplementary Figure S1: (a) HOMO-3, HOMO-2, HOMO-1, and LUMO+4 of BCzT and (b) HOMO-3, HOMO-2, and HOMO-1 of CzT calculated with the CAM-B3LYP functional and cc-pVDZ basis set. 
Ultraviolet-visible and photoluminescence spectra of $\mathrm{BCzT}$ measured in toluene solution

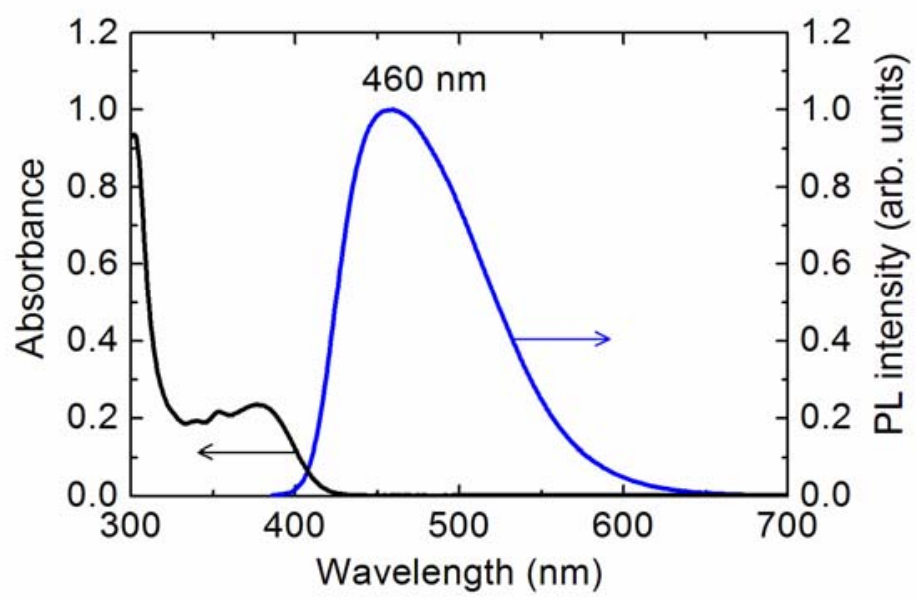

Supplementary Figure S2: UV-visible and photoluminescence spectra of BCzT measured in a toluene solution. The excitation wavelength was $376 \mathrm{~nm}$. 
Fluorescence and phosphorescence spectra of a $6 \mathrm{wt} \%$ BCzT:DPEPO film

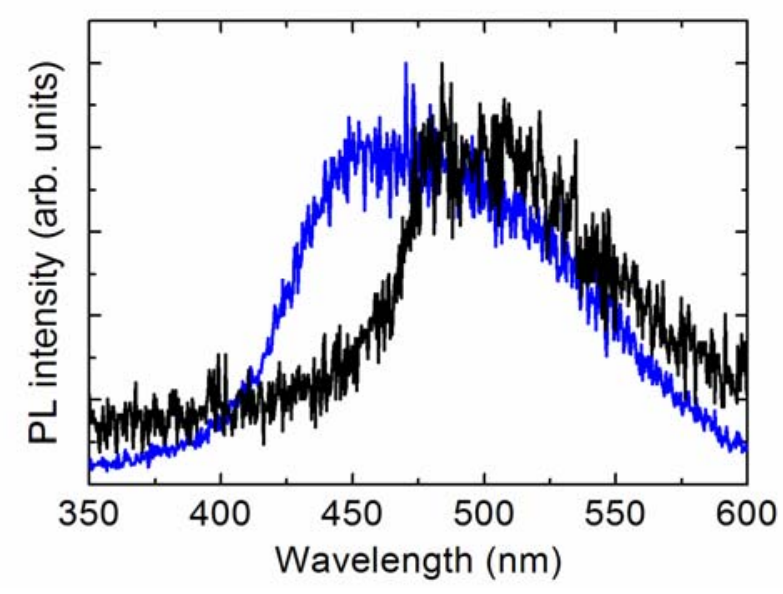

Supplementary Figure S3: Fluorescence and phosphorescence spectra of a 6 wt \% BCzT:DPEPO film measured at $15 \mathrm{~K}$. The blue and black lines show the fluorescence and phosphorescence spectra, respectively. An yttrium-aluminum-garnet laser operating at a wavelength of $355 \mathrm{~nm}$ (LS-2132, LOTIS TII, Belarus) was used as the excitation source. 
Photoluminescence and electroluminescence processes for BCzT

Photoluminescence
(a) $\frac{S_{1}}{1}$
(b) $\mathrm{s}_{1}$

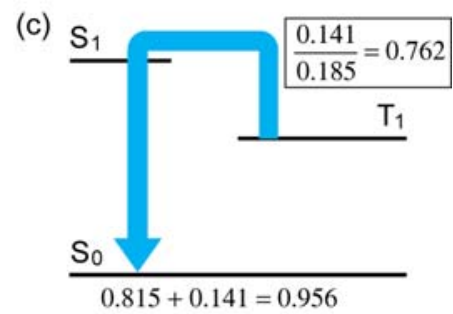
Electroluminescence
(d)

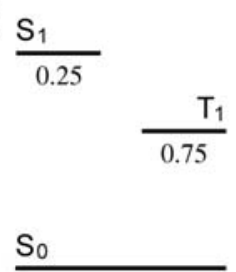
(e)

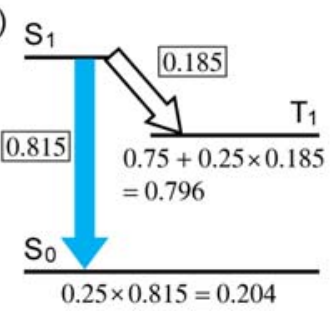
(f)

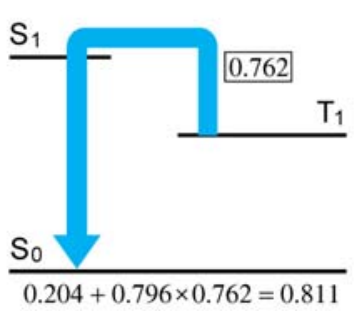

Supplementary Figure S4: $(\mathrm{a}-\mathrm{c})$ Photoluminescence process for the 6 wt \% BCzT:DPEPO thin film. (d-f) Electroluminescence process for the BCzT-based OLED. 
External quantum efficiency and current density characteristics of a TCzT-based OLED
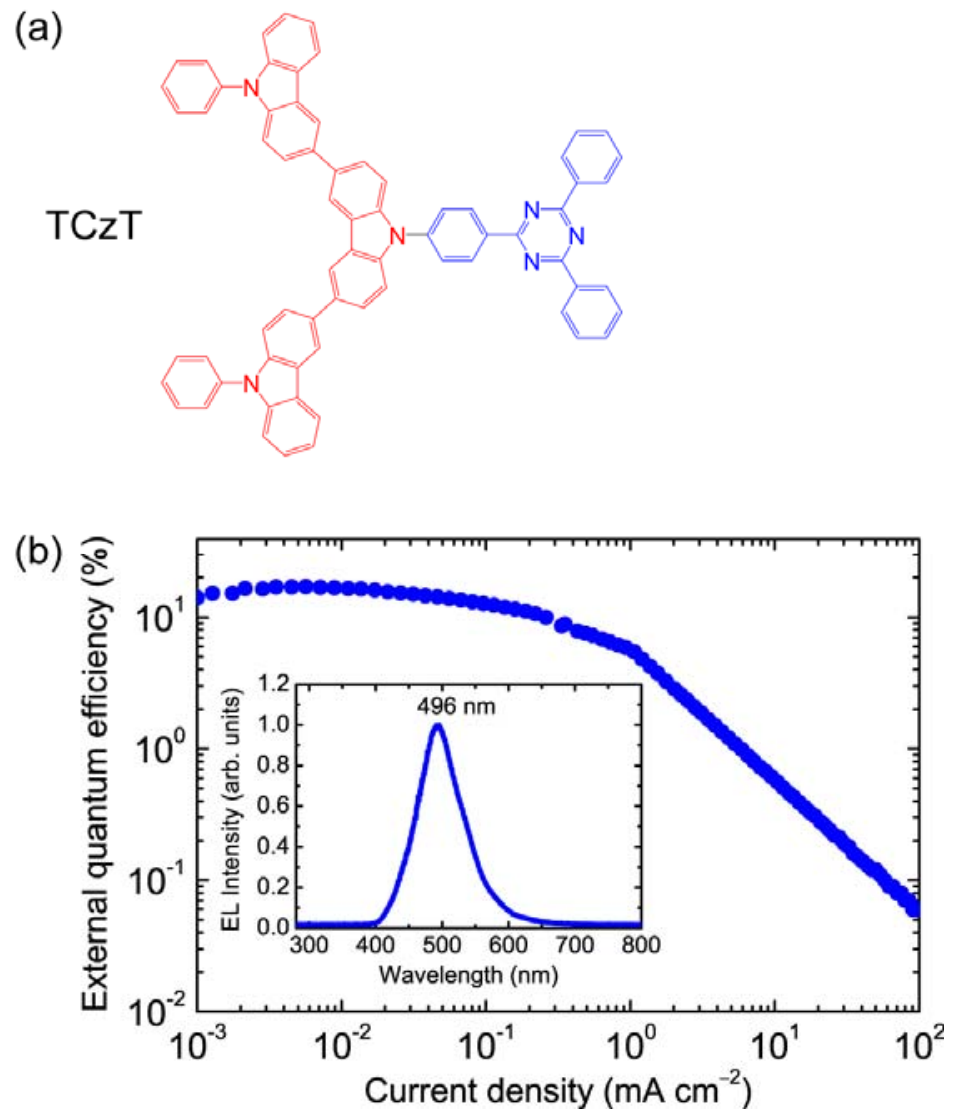

Supplementary Figure S5: (a) Chemical structure of TCzT. (b) EQE-current density characteristics of the TCzT-based OLED. The device structure is ITO $(100 \mathrm{~nm}) / \alpha-\mathrm{NPD}$ $(35 \mathrm{~nm}) / \mathrm{m}$-CBP $(10 \mathrm{~nm}) / 6 \mathrm{wt} \%$-TCzT:DPEPO $(20 \mathrm{~nm}) / \mathrm{TPBi}(35 \mathrm{~nm}) / \mathrm{LiF}(0.5 \mathrm{~nm}) / \mathrm{Al}$ $(100 \mathrm{~nm})$. The inset figure shows the electroluminescence spectrum of the device measured at a current density of $100 \mathrm{~mA} \mathrm{~cm}^{-2}$.

\section{Reference}

(1) Tanaka, H.; Shizu, K.; Nakanotani, H.; Adachi, C. Dual Intramolecular Charge-Transfer Fluorescence Derived from a Phenothiazine-Triphenyltriazine Derivative. J. Phys. Chem. C 2014, 118, 15985-15994. 